\title{
Multiple-Set Split Feasibility Problems for $\kappa$-Strictly Pseudononspreading Mapping in Hilbert Spaces
}

\author{
Jing Quan, ${ }^{1}$ Shih-sen Chang, ${ }^{2}$ and Xiang Zhang ${ }^{3}$ \\ ${ }^{1}$ Institute for Mathematics, Yibin University, Yibin, Sichuan 644007, China \\ ${ }^{2}$ College of Statistics and Mathematics, Yunnan University of Finance and Economics, Kunming, Yunnan 650221, China \\ ${ }^{3}$ Department of Mathematics, Guizhou Normal University, Guiyang 550014, China
}

Correspondence should be addressed to Shih-sen Chang; changss2013@aliyun.com

Received 15 July 2013; Accepted 2 September 2013

Academic Editor: E. Karapinar

Copyright (C) 2013 Jing Quan et al. This is an open access article distributed under the Creative Commons Attribution License, which permits unrestricted use, distribution, and reproduction in any medium, provided the original work is properly cited.

The purpose of this paper is to prove some weak and strong convergence theorems for solving the multiple-set split feasibility problems for $\kappa$-strictly pseudononspreading mapping in infinite-dimensional Hilbert spaces by using the proposed iterative method. The main results presented in this paper extend and improve the corresponding results of Xu et al. (2006), of Osilike et al. (2011), and of many other authors.

\section{Introduction and Preliminaries}

Censor and Elfving first introduced the split feasibility problem (SFP) [1] in finite dimensional spaces for modeling inverse problems. The SFP can be used in various disciplines such as medical image reconstruction [2], image restoration, computer tomograph, and radiation therapy treatment planning [3-5]. The multiple-set split feasibility problem (MSSFP) was studied in [4-6].

In the sequel, we always assume that $H_{1}, H_{2}$ are two real Hilbert spaces and denote by " $\rightarrow$ " and " $\rightarrow$ " the strong and weak convergence, respectively.

The so-called multiple-set split feasibility problem (MSSFP) is to find $x^{*} \in C$ such that $A x^{*} \in Q$, where $A: H_{1} \rightarrow H_{2}$ is a bounded linear operator, $S_{i}$ and $T_{i}, i=$ $1,2, \ldots, N$ are the families of mappings, $S_{i}: H_{1} \rightarrow H_{1}$ and $T_{i}: H_{2} \rightarrow H_{2}, C:=\bigcap_{i=1}^{N} F\left(S_{i}\right)$, and $Q:=\bigcap_{i=1}^{N} F\left(T_{i}\right)$, where $F\left(S_{i}\right)=\left\{x \in H_{1}: S_{i} x=x\right\}$ and $F\left(T_{i}\right)=\left\{y \in H_{2}: T_{i} y=y\right\}$ denote the sets of fixed points of $S_{i}$ and $T_{i}$, respectively. In the sequel, we use $\Gamma$ to denote the set of solutions of the MSSFP; that is,

$$
\Gamma=\{x \in C: A x \in Q\} .
$$

Recently, Kohsaka and Takahashi $[7,8]$ introduced an important class of mappings which is called the class of nonspreading mappings.

Definition 1 (see $[7,8])$. Let $K$ to be a nonempty closed convex subset of a Hilbert space $H$. A mapping $T: K \rightarrow K$ is said to be nonspreading, if

$$
2\|T x-T y\|^{2} \leq\|T x-y\|^{2}+\|T y-x\|^{2}, \quad \forall x, y \in K .
$$

In [9], Iemoto and Takahashi proved that this definition is equivalent to the following.

Definition 2 (see [9]). Let $K$ be a nonempty closed convex subset of a Hilbert space $H$. A mapping $T: K \rightarrow K$ is said to be nonspreading, if

$$
\|T x-T y\|^{2} \leq\|x-y\|^{2}+2\langle x-T x, y-T y\rangle, \quad \forall x, y \in K .
$$

Browder and Petryshyn [10] proposed the following $\kappa$ strictly pseudononspreading mapping. 
Definition 3 (see [10]). Let $H$ be a real Hilbert space. We say that a mapping $T: D(T) \subset H \rightarrow H$ is $\kappa$-strictly pseudononspreading if there exists $\kappa \in[0,1)$, such that

$$
\begin{aligned}
\|T x-T y\|^{2} \leq & \|x-y\|^{2}+\kappa\|x-T x-(y-T y)\|^{2} \\
& +2\langle x-T x, y-T y\rangle, \quad \forall x, y \in D(T) .
\end{aligned}
$$

Clearly every nonspreading mapping is $\kappa$-strictly pseudononspreading.

Osilike and Isiogugu [11] introduced a class of nonspreading type mappings which is more general than that of the mappings studied in [12] in Hilbert spaces and proved some weak and strong convergence theorems in real Hilbert spaces. Recently, the split feasibility problem also was considered in the work by Deepho and Kumam $[13,14]$ and Sunthrayuth et al. [15], and some weak and strong convergence theorems are proved in real Hilbert spaces.

The purpose of this paper is to study the multiple-set split feasibility problem (MSSFP) for $\kappa$-strictly pseudononspreading mappings in the framework of infinite dimensional Hilbert spaces.

In the sequel, we recall some definitions, notations, and conclusions which will be needed in proving our main results.

Definition 4 (see [3]). Let $E$ be a real Banach space. A mapping $T$ with domain $D(T)$ and range $R(T)$ in $E$ is said to be demiclosed at origin if for any sequence $\left\{x_{n}\right\}$ in $D(T)$ which converges weakly to a point $x^{*} \in D(T)$ and $\left\|(I-T) x_{n}\right\|$ converges strongly to 0 , then $T x^{*}=x^{*}$.

Definition 5. A Banach space $E$ is said to have Opial property if, for any sequence $\left\{x_{n}\right\}$ with $x_{n} \rightarrow x^{*}$, we have

$$
\liminf _{n \rightarrow \infty}\left\|x_{n}-x^{*}\right\|<\liminf _{n \rightarrow \infty}\left\|x_{n}-y\right\|
$$

for all $y \in E$ with $y \neq x^{*}$.

Remark 6. It is well known that each Hilbert space possesses Opial property.

Definition 7. A mapping $S: K \rightarrow K$ is said to be semicompact, if, for any bounded sequence $\left\{x_{n}\right\} \subset K$ with $\lim _{n \rightarrow \infty}\left\|x_{n}-S x_{n}\right\|=0$, there exists a subsequence $\left\{x_{n_{i}}\right\} \subset$ $\left\{x_{n}\right\}$ such that $\left\{x_{n_{i}}\right\}$ converges strongly to some point $x^{*} \in K$.

Lemma 8 (see [11]). Let $H$ be a real Hilbert space; then the following results hold.

(i) For all $x, y \in H$ and for all $t \in[0,1]$,

$$
\begin{array}{r}
\|t x+(1-t) y\|^{2}=t\|x\|^{2}+(1-t)\|y\|^{2} \\
-t(1-t)\|x-y\|^{2} .
\end{array}
$$

(ii) $\|x+y\|^{2} \leq\|x\|^{2}+2\langle y, x+y\rangle$. (iii) If $\left\{x_{n}\right\}_{n=1}^{\infty}$ is a sequence in $H$ which converges weakly to $z \in H$, then

$$
\begin{aligned}
\limsup _{n \rightarrow \infty}\left\|x_{n}-y\right\|^{2}= & \limsup _{n \rightarrow \infty}\left\|x_{n}-z\right\|^{2} \\
& +\|z-y\|^{2}, \quad \forall y \in H .
\end{aligned}
$$

Definition 9. Let $K$ be a nonempty closed convex subset of a real Hilbert space $H$. The metric projection $P_{K}: H \rightarrow K$ is a mapping such that, for each $x \in H, P_{K} x$ is the unique point in $K$ such that $\left\|x-P_{K} x\right\| \leq\|x-y\|, \forall y \in K$. It is known that, for each $x \in H$,

$$
\left\langle x-P_{K} x, y-P_{K} x\right\rangle \leq 0, \quad \forall y \in K
$$

Lemma 10 (see [11]). Let $K$ be a nonempty closed convex subset of a real Hilbert space $H$, and let $T: K \rightarrow K$ be a $\kappa$-strictly pseudononspreading mapping. If $F(T) \neq \emptyset$, then it is closed and convex.

Lemma 11 (see [11]). Let $K$ be a nonempty closed convex subset of a real Hilbert space $H$, and let $T: K \rightarrow K$ be a $\kappa$-strictly pseudononspreading mapping. Then $(I-T)$ is demiclosed at 0.

\section{Main Results}

Theorem 12. Let $H_{1}, H_{2}, A,\left\{S_{i}\right\},\left\{T_{i}\right\}, C, Q$ be the same as aforementioned. For each $i=1,2, \ldots, N$, let $T_{i}$ be a $\kappa_{i}$-strictly pseudononspreading mapping and let $S_{i}$ be a $\varrho_{i^{-}}$ strictly pseudononspreading mapping. Let $\left\{x_{n}\right\}$ be the sequence generated by

$$
\begin{gathered}
x_{1} \in H_{1} \text { chosen arbitrarily, } \\
u_{n}=x_{n}+\gamma A^{*}\left(T_{n(\bmod N)}-I\right) A x_{n}, \\
x_{n+1}=\left(1-\alpha_{n}\right) u_{n}+\alpha_{n} S_{n(\bmod N)} u_{n},
\end{gathered}
$$

where $\gamma \in(0,(1-\kappa) / \lambda)$ with $\lambda$ being the spectral of the operator $A^{*} A$ and $\kappa=\max \left\{\kappa_{1}, \kappa_{2}, \ldots, \kappa_{N}\right\} \in(0,1)$, and $\alpha_{n}$ is a sequence in $(0,1-\varrho]$ with $\varrho=\max \left\{\varrho_{1}, \varrho_{2}, \ldots, \varrho_{N}\right\} \in(0,1)$. If $\Gamma \neq \emptyset$ (where $\Gamma$ is the set of solutions of the MSSFP defined by (1)), then the sequence $\left\{x_{n}\right\}$ converges weakly to a point $x^{*} \in \Gamma$.

Proof. The proof is divided into four steps.

(I) We first prove that $\lim _{n \rightarrow \infty}\left\|x_{n}-p\right\|$ exists for any $p \in$ $\Gamma$.

Since $p \in \Gamma, p \in C:=\bigcap_{i=1}^{N} F\left(S_{i}\right)$ and $A p \in Q:=$ $\bigcap_{i=1}^{N} F\left(T_{i}\right)$. It follows from (9) that

$$
\begin{aligned}
\left\|x_{n+1}-p\right\|^{2}= & \left\|u_{n}-p+\alpha_{n}\left(S_{n(\bmod N)} u_{n}-u_{n}\right)\right\|^{2} \\
= & \left\|u_{n}-p\right\|^{2}+2 \alpha_{n}\left\langle u_{n}-p, S_{n(\bmod N)} u_{n}-u_{n}\right\rangle \\
& +\alpha_{n}^{2}\left\|u_{n}-S_{n(\bmod N)} u_{n}\right\|^{2} .
\end{aligned}
$$


Because $S_{i}$ is $\varrho_{i}$-strictly pseudononspreading, for each $v \in$ $H_{1}$, we have

$$
\begin{aligned}
& \left\|S_{n(\bmod N)} u_{n}-S_{n(\bmod N)} v\right\|^{2} \\
& \leq\left\|u_{n}-v\right\|^{2}+\varrho\left\|u_{n}-S_{n(\bmod N)} u_{n}-\left(v-S_{n(\bmod N)} v\right)\right\|^{2} \\
& \quad+2\left\langle u_{n}-S_{n(\bmod N)} u_{n}, v-S_{n(\bmod N)} v\right\rangle .
\end{aligned}
$$

Taking $v=p$, we have

$$
\left\|S_{n(\bmod N)} u_{n}-p\right\|^{2} \leq\left\|u_{n}-p\right\|^{2}+\varrho\left\|u_{n}-S_{n(\bmod N)} u_{n}\right\|^{2} .
$$

This implies that

$$
\begin{aligned}
\left\|S_{n(\bmod N)} u_{n}-p\right\|^{2} \\
=\left\|S_{n(\bmod N)} u_{n}-u_{n}+u_{n}-p\right\|^{2} \\
=\left\|S_{n(\bmod N)} u_{n}-u_{n}\right\|^{2}+2\left\langle S_{n(\bmod N)} u_{n}-u_{n}, u_{n}-p\right\rangle \\
\quad+\left\|u_{n}-p\right\|^{2} \\
\leq\left\|u_{n}-p\right\|^{2}+\varrho\left\|u_{n}-S_{n(\bmod N)} u_{n}\right\|^{2} .
\end{aligned}
$$

Thus it yields that

$$
\begin{aligned}
& 2 \alpha_{n}\left\langle S_{n(\bmod N)} u_{n}-u_{n}, u_{n}-p\right\rangle \\
& \quad \leq \alpha_{n}(\varrho-1)\left\|u_{n}-S_{n(\bmod N)} u_{n}\right\|^{2} .
\end{aligned}
$$

Substituting (14) into (10) and simplifying, we have

$$
\begin{aligned}
\left\|x_{n+1}-p\right\|^{2} \leq & \left\|u_{n}-p\right\|^{2}+\alpha_{n}(\varrho-1)\left\|u_{n}-S_{n(\bmod N)} u_{n}\right\|^{2} \\
& +\alpha_{n}^{2}\left\|u_{n}-S_{n(\bmod N)} u_{n}\right\|^{2} \\
= & \left\|u_{n}-p\right\|^{2}-\alpha_{n}\left(1-\varrho-\alpha_{n}\right)\left\|u_{n}-S_{n(\bmod N)} u_{n}\right\|^{2} .
\end{aligned}
$$

On the other hand,

$$
\begin{aligned}
\| u_{n}- & p \|^{2} \\
= & \left\|x_{n}-p+\gamma A^{*}\left(T_{n(\bmod N)}-I\right) A x_{n}\right\|^{2} \\
= & \left\|x_{n}-p\right\|^{2}+2 \gamma\left\langle x_{n}-p, A^{*}\left(T_{n(\bmod N)}-I\right) A x_{n}\right\rangle \\
& +\gamma^{2}\left\|A^{*}\left(T_{n(\bmod N)}-I\right) A x_{n}\right\|^{2} \\
= & \left\|x_{n}-p\right\|^{2}+2 \gamma\left\langle x_{n}-p, A^{*}\left(T_{n(\bmod N)}-I\right) A x_{n}\right\rangle \\
& +\gamma^{2}\left\langle A^{*}\left(T_{n(\bmod N)}-I\right) A x_{n}, A^{*}\left(T_{n(\bmod N)}-I\right) A x_{n}\right\rangle \\
= & \left\|x_{n}-p\right\|^{2}+2 \gamma\left\langle x_{n}-p, A^{*}\left(T_{n(\bmod N)}-I\right) A x_{n}\right\rangle \\
& +\gamma^{2}\left\langle A A^{*}\left(T_{n(\bmod N)}-I\right) A x_{n},\left(T_{n(\bmod N)}-I\right) A x_{n}\right\rangle
\end{aligned}
$$

$$
\begin{aligned}
\leq & \left\|x_{n}-p\right\|^{2}+2 \gamma\left\langle x_{n}-p, A^{*}\left(T_{n(\bmod N)}-I\right) A x_{n}\right\rangle \\
& +\gamma^{2}\|A\|^{2}\left\|\left(T_{n(\bmod N)}-I\right) A x_{n}\right\|^{2} .
\end{aligned}
$$

Since $T_{i}$ is $\kappa_{i}$-strictly pseudononspreading and noting that $A p \in \bigcap_{i=1}^{N} F\left(T_{i}\right)$, we have

$$
\begin{aligned}
& \left\|T_{n(\bmod N)} A x_{n}-A p\right\|^{2} \\
& =\left\|T_{n(\bmod N)} A x_{n}-A x_{n}+A x_{n}-A p\right\|^{2} \\
& =\left\|T_{n(\bmod N)} A x_{n}-A x_{n}\right\|^{2}+\left\|A x_{n}-A p\right\|^{2} \\
& \quad+2\left\langle T_{n(\bmod N)} A x_{n}-A x_{n}, A x_{n}-A p\right\rangle \\
& \leq\left\|A x_{n}-A p\right\|^{2}+\kappa\left\|T_{n(\bmod N)} A x_{n}-A x_{n}\right\|^{2} .
\end{aligned}
$$

This leads to

$$
\begin{aligned}
& \left\langle T_{n(\bmod N)} A x_{n}-A x_{n}, A x_{n}-A p\right\rangle \\
& \quad \leq \frac{\kappa-1}{2}\left\|T_{n(\bmod N)} A x_{n}-A x_{n}\right\|^{2} .
\end{aligned}
$$

By (18), we have

$$
\begin{aligned}
& \left\langle T_{n(\bmod N)} A x_{n}-A x_{n}, T_{n(\bmod N)} A x_{n}-A p\right\rangle \\
& =\left\langle T_{n(\bmod N)} A x_{n}-A x_{n}, T_{n(\bmod N)} A x_{n}+A x_{n}-A x_{n}-A p\right\rangle \\
& =\left\|\left(T_{n(\bmod N)}-I\right) A x_{n}\right\|^{2}+\left\langle T_{n(\bmod N)} A x_{n}-A x_{n}, A x_{n}-A p\right\rangle \\
& \leq\left\|\left(T_{n(\bmod N)}-I\right) A x_{n}\right\|^{2}+\frac{\kappa-1}{2}\left\|\left(T_{n(\bmod N)}-I\right) A x_{n}\right\|^{2} \\
& =\frac{\kappa+1}{2}\left\|\left(T_{n(\bmod N)}-I\right) A x_{n}\right\|^{2} .
\end{aligned}
$$

It follows from (19) that

$$
\begin{aligned}
2 \gamma\langle & \left.x_{n}-p, A^{*}\left(T_{n(\bmod N)}-I\right) A x_{n}\right\rangle \\
= & 2 \gamma\left\langle A\left(x_{n}-p\right),\left(T_{n(\bmod N)}-I\right) A x_{n}\right\rangle \\
= & 2 \gamma\left\langle A\left(x_{n}-p\right)+\left(T_{n(\bmod N)}-I\right) A x_{n}\right. \\
& \left.\quad-\left(T_{n(\bmod N)}-I\right) A x_{n},\left(T_{n(\bmod N)}-I\right) A x_{n}\right\rangle \\
= & 2 \gamma\left\langle T_{n(\bmod N)} A x_{n}-A p,\left(T_{n(\bmod N)}-I\right) A x_{n}\right\rangle \\
- & 2 \gamma\left\|\left(T_{n(\bmod N)}-I\right) A x_{n}\right\|^{2} \\
\leq & {[\gamma(1+\kappa)-2 \gamma]\left\|\left(T_{n(\bmod N)}-I\right) A x_{n}\right\|^{2} } \\
= & {[\gamma(\kappa-1)]\left\|\left(T_{n(\bmod N)}-I\right) A x_{n}\right\|^{2} . }
\end{aligned}
$$


By using (15), (16), (19), and (20), we have

$$
\begin{aligned}
& \left\|x_{n+1}-p\right\|^{2} \\
& \leq\left\|x_{n}-p\right\|^{2}+\gamma^{2}\|A\|^{2}\left\|\left(T_{n(\bmod N)}-I\right) A x_{n}\right\|^{2} \\
& \quad+[\gamma(\kappa-1)]\left\|\left(T_{n(\bmod N)}-I\right) A x_{n}\right\|^{2} \\
& \quad-\alpha_{n}\left(1-\sigma-\alpha_{n}\right)\left\|u_{n}-S_{n(\bmod N)} u_{n}\right\|^{2} \\
& \leq\left\|x_{n}-p\right\|^{2}-\gamma\left(1-\kappa-\gamma\|A\|^{2}\right)\left\|\left(T_{n(\bmod N)}-I\right) A x_{n}\right\|^{2} \\
& \quad-\alpha_{n}\left(1-\varrho-\alpha_{n}\right)\left\|u_{n}-S_{n(\bmod N)} u_{n}\right\|^{2} \\
& \leq\left\|x_{n}-p\right\|^{2} .
\end{aligned}
$$

This shows that $\lim _{n \rightarrow \infty}\left\|x_{n}-p\right\|$ exists.

(II) We now prove that $\lim _{n \rightarrow \infty}\left\|u_{n}-p\right\|$ exists.

In fact, by (21), we have

$$
\begin{aligned}
& {\left[\gamma\left(1-\kappa-\gamma\|A\|^{2}\right)\right]\left\|\left(T_{n(\bmod N)}-I\right) A x_{n}\right\|^{2}} \\
& \quad+\alpha_{n}\left(1-\varrho-\alpha_{n}\right)\left\|u_{n}-S_{n(\bmod N)} u_{n}\right\|^{2} \\
& \leq\left\|x_{n}-p\right\|^{2}-\left\|x_{n+1}-p\right\|^{2} .
\end{aligned}
$$

This implies that

$$
\begin{gathered}
\lim _{n \rightarrow \infty}\left\|\left(T_{n(\bmod N)}-I\right) A x_{n}\right\|=0, \\
\lim _{n \rightarrow \infty}\left\|u_{n}-S_{n(\bmod N)} u_{n}\right\|=0 .
\end{gathered}
$$

By virtue of (16), (23), and (24), it follows that $\lim _{n \rightarrow \infty}\left\|u_{n}-p\right\|$ exists and $\lim _{n \rightarrow \infty}\left\|x_{n}-p\right\|=\lim _{n \rightarrow \infty} \| u_{n}-$ $p \|$.

(III) Now, we prove that $\lim _{n \rightarrow \infty}\left\|x_{n+1}-x_{n}\right\|=0$ and $\lim _{n \rightarrow \infty}\left\|u_{n+1}-u_{n}\right\|=0$.

In fact, it follows from (9) that

$$
\begin{aligned}
& \left\|x_{n+1}-x_{n}\right\| \\
& =\left\|\left(1-\alpha_{n}\right) u_{n}+\alpha_{n} S_{n(\bmod N)} u_{n}-x_{n}\right\| \\
& =\|\left(1-\alpha_{n}\right)\left(x_{n}+\gamma A^{*}\left(T_{n(\bmod N)}-I\right) A x_{n}\right) \\
& +\alpha_{n} S_{n(\bmod N)} u_{n}-x_{n} \| \\
& =\|\left(1-\alpha_{n}\right)\left(\gamma A^{*}\left(T_{n(\bmod N)}-I\right) A x_{n}\right) \\
& +\alpha_{n}\left(S_{n(\bmod N)} u_{n}-x_{n}\right) \| \\
& =\|\left(1-\alpha_{n}\right)\left(\gamma A^{*}\left(T_{n(\bmod N)}-I\right) A x_{n}\right) \\
& +\alpha_{n}\left(S_{n(\bmod N)} u_{n}-u_{n}\right)+\alpha_{n}\left(u_{n}-x_{n}\right) \| \\
& =\|\left(1-\alpha_{n}\right)\left(\gamma A^{*}\left(T_{n(\bmod N)}-I\right) A x_{n}\right) \\
& +\alpha_{n}\left(S_{n(\bmod N)} u_{n}-u_{n}\right) \\
& +\alpha_{n} \gamma A^{*}\left(T_{n(\bmod N)}-I\right) A x_{n} \| \\
& =\left\|\gamma A^{*}\left(T_{n(\bmod N)}-I\right) A x_{n}+\alpha_{n}\left(S_{n(\bmod N)} u_{n}-u_{n}\right)\right\| .
\end{aligned}
$$

This together with (23) and (24) leads to $\lim _{n \rightarrow \infty} \| x_{n+1}-$ $x_{n} \|=0$.

Similarly, it follows from (9), (23), and (25) that

$$
\begin{aligned}
& \left\|u_{n+1}-u_{n}\right\| \\
& =\| x_{n+1}+\gamma A^{*}\left(T_{n+1(\bmod N)}-I\right) A x_{n+1} \\
& \quad-\left[x_{n}+\gamma A^{*}\left(T_{n(\bmod N)}-I\right) A x_{n}\right] \| \\
& \leq\left\|x_{n+1}-x_{n}\right\|+\left\|\gamma A^{*}\left(T_{n+1(\bmod N)}-I\right) A x_{n+1}\right\| \\
& \quad+\left\|\left[\gamma A^{*}\left(T_{n(\bmod N)}-I\right) A x_{n}\right]\right\| \\
& \longrightarrow 0 \quad(\operatorname{as} n \rightarrow \infty) .
\end{aligned}
$$

(IV) Finally, we prove that $x_{n} \rightarrow x^{*}$ and $u_{n} \rightarrow x^{*}$, which is a solution of the MSSFP.

In fact, since $\left\{u_{n}\right\}$ is bounded, there exists a subsequence $\left\{u_{n_{i}}\right\} \subset\left\{u_{n}\right\}$ such that $\left\{u_{n_{i}}\right\} \rightarrow x^{*} \in H_{1}$. Hence, for any positive integer $j=1,2, \ldots, N$, there exists a subsequence $\left\{n_{i}(j)\right\} \subset\left\{n_{i}\right\}$ with $n_{i}(j)(\bmod N)=j$ such that $\left\{u_{n_{i}(j)}\right\} \rightarrow x^{*}$. Again, by (24) we know that $\left\|u_{i N+j}-S_{j} u_{i N+j}\right\| \rightarrow 0$, as $n \rightarrow \infty$; therefore, we have that

$$
\left\|u_{n_{i}(j)}-S_{j} u_{n_{i}(j)}\right\| \longrightarrow 0, \quad \text { as } n_{i(j)} \longrightarrow \infty
$$

Since $S_{j}$ is demiclosed at zero, it follows that $x \in F\left(S_{j}\right)$. By the arbitrariness of $j=1,2, \ldots, N$, we have

$$
x^{*} \in C:=\bigcap_{i=1}^{N} F\left(S_{i}\right) \text {. }
$$

Moreover, from (9) and (24), we have $x_{n_{i}}=u_{n_{i}}-$ $\gamma A^{*}\left(T_{n_{i}(\bmod N)}-I\right) A x_{n_{i}} \rightarrow x^{*}$. Since $A$ is a bounded linear operator, it follows that $A x_{n_{i}} \rightarrow A x^{*}$. For any positive integer $k=1,2, \ldots, N$, there exists a subsequence $\left\{x_{n_{i}(k)}\right\} \subset\left\{x_{n_{i}}\right\}$ with $n_{i}(k)(\bmod N)=k$ such that $A x_{n_{i}(k)} \rightarrow A x^{*}$ and $\left\|A x_{n_{i}(k)}-T_{k} A x_{n_{i}(k)}\right\| \rightarrow 0$. Since $T_{k}$ is demiclosed at zero, we have $A x^{*} \in F\left(T_{k}\right)$. By the arbitrariness of $k \in\{1,2, \ldots, N\}$, it follows that $A x^{*} \in Q:=\bigcap_{k=1}^{N} F\left(T_{k}\right)$. This together with $x^{*} \in C$ shows that $x^{*} \in \Gamma$; that is, $x^{*}$ is a solution to the MSSFP.

Now, we prove that $x_{n} \rightarrow x^{*}$ and $u_{n} \rightarrow x^{*}$.

Suppose on the contrary that there exists another subsequence $\left\{u_{n_{l}}\right\} \subset\left\{u_{n}\right\}$ such that $\left\{u_{n_{l}}\right\} \rightarrow y^{*} \in \Gamma$ with $y^{*} \neq x^{*}$. Consequently, by virtue of the existence of $\lim _{n \rightarrow \infty}\left\|x_{n}-p\right\|$ and the Opial property of Hilbert space, we have

$$
\begin{aligned}
\liminf _{n_{i} \rightarrow \infty}\left\|u_{n_{i}}-x^{*}\right\| & <\liminf _{n_{i} \rightarrow \infty}\left\|u_{n_{i}}-y^{*}\right\| \\
& =\liminf _{n \rightarrow \infty}\left\|u_{n}-y^{*}\right\|=\liminf _{n_{j} \rightarrow \infty}\left\|u_{n_{j}}-y^{*}\right\| \\
& <\liminf _{n_{j} \rightarrow \infty}\left\|u_{n_{j}}-x^{*}\right\|=\liminf _{n \rightarrow \infty}\left\|u_{n}-x^{*}\right\| \\
& =\liminf _{n_{i} \rightarrow \infty}\left\|u_{n_{i}}-x^{*}\right\| .
\end{aligned}
$$


This is a contradiction. Therefore $u_{n} \rightarrow x^{*}$. By (9) and (24), we have

$$
x_{n}=u_{n}-\gamma A^{*}\left(T_{n(\bmod N)}^{n}-I\right) A x_{n}-x^{*} .
$$

Therefore, the conclusion follows.

This completes the proof of Theorem 12.

Theorem 13. Let $H_{1}, H_{2}, A,\left\{S_{i}\right\},\left\{T_{i}\right\}, C, Q$ be the same as in Theorem 12. For each $i=1,2, \ldots, N$, let $T_{i}$ be a $\kappa_{i^{-}}$ strictly pseudononspreading mapping, and $S_{i}$ be a $\varrho_{i}$-strictly pseudononspreading mapping. Let $\left\{x_{n}\right\}$ be the sequence generated by

$$
\begin{gathered}
x_{1} \in H_{1} \text { chosen arbitrarily, } \\
u_{n}=x_{n}+\gamma A^{*}\left(T_{n(\bmod N)}-I\right) A x_{n}, \\
x_{n+1}=\left(1-\alpha_{n}\right) u_{n}+\alpha_{n} S_{n(\bmod N)} u_{n},
\end{gathered}
$$

where $\gamma \in(0,(1-\kappa) / \lambda)$ with $\lambda$ being the spectral of the operator $A^{*} A$ and $\kappa=\max \left\{\kappa_{1}, \kappa_{2}, \ldots, \kappa_{N}\right\} \in(0,1)$, and $\left\{\alpha_{n}\right\}$ is a sequence in $(0,1-\varrho]$ with $\varrho=\max \left\{\varrho_{1}, \varrho_{2}, \ldots, \varrho_{N}\right\} \in(0,1)$. If $\Gamma \neq \emptyset$ and if there exists a positive integer $j$ such that $S_{j}$ is semicompact, then the sequence $\left\{x_{n}\right\}$ converges strongly to a point $x^{*} \in \Gamma$.

Proof. Without loss of generality, we can assume that $S_{1}$ is semicompact. It follows from (27) that

$$
\left\|u_{n_{i}(1)}-S_{1} u_{n_{i}(1)}\right\| \longrightarrow 0, \quad n_{i(1)} \longrightarrow \infty .
$$

Therefore, there exists a subsequence of $\left\{u_{n_{i}(1)}\right\}$ (for the sake of convenience, we still denote it by $\left.\left\{u_{n_{i}(1)}\right\}\right)$, such that $u_{n_{i}(1)} \rightarrow u^{*} \in H_{1}$. Since $u_{n_{i}(1)} \rightarrow x^{*}, x^{*}=u^{*}$, and so $u_{n_{i}(1)} \rightarrow x^{*} \in \Gamma$. By virtue of the existence of $\lim _{n \rightarrow \infty} \| x_{n}-$ $p \|$, we know that

$$
\lim _{n \rightarrow \infty}\left\|u_{n}-x^{*}\right\|=0, \quad \lim _{n \rightarrow \infty}\left\|x_{n}-x^{*}\right\|=0 .
$$

That is, $\left\{u_{n}\right\}$ and $\left\{x_{n}\right\}$ both converge strongly to the point $x^{*} \in \Gamma$. This completes the proof of Theorem 13 .

\section{Conflict of Interests}

The authors declare that they have no conflict of interests.

\section{Authors' Contribution}

All the authors contributed equally and significantly in writing this paper. All the authors read and approved the final paper.

\section{Acknowledgments}

This work was supported by the Natural Science Foundation of Yibin University (no. 2011B07) and the Scientific Research Fund Project of Sichuan Provincial Education Department (no. 12ZB345) and the Fund of Science and Technology Department of Guizhou Province ([2013] 2223).

\section{References}

[1] Y. Censor and T. Elfving, "A multiprojection algorithm using Bregman projections in a product space," Numerical Algorithms, vol. 8, no. 2-4, pp. 221-239, 1994.

[2] C. Byrne, "Iterative oblique projection onto convex sets and the split feasibility problem," Inverse Problems, vol. 18, no. 2, pp. 441453, 2002.

[3] Y. Censor, T. Bortfeld, B. Martin, and A. Trofimov, "A unified approach for inversion problems in intensity-modulated radiation therapy," Physics in Medicine and Biology, vol. 51, no. 10, pp. 2353-2365, 2006.

[4] Y. Censor, T. Elfving, N. Kopf, and T. Bortfeld, “The multiplesets split feasibility problem and its applications for inverse problems," Inverse Problems, vol. 21, no. 6, pp. 2071-2084, 2005.

[5] Y. Censor, A. Motova, and A. Segal, "Perturbed projections and subgradient projections for the multiple-sets split feasibility problem," Journal of Mathematical Analysis and Applications, vol. 327, no. 2, pp. 1244-1256, 2007.

[6] H.-K. Xu, "A variable Krasnoselskii-Mann algorithm and the multiple-set split feasibility problem," Inverse Problems, vol. 22, no. 6, pp. 2021-2034, 2006.

[7] F. Kohsaka and W. Takahashi, "Fixed point theorems for a class of nonlinear mappings related to maximal monotone operators in Banach spaces," Archiv der Mathematik, vol. 91, no. 2, pp. 166177, 2008.

[8] F. Kohsaka and W. Takahashi, "Existence and approximation of fixed points of firmly nonexpansive-type mappings in Banach spaces," SIAM Journal on Optimization, vol. 19, no. 2, pp. 824835, 2008.

[9] S. Iemoto and W. Takahashi, "Approximating common fixed points of nonexpansive mappings and nonspreading mappings in a Hilbert space," Nonlinear Analysis: Theory, Methods \& Applications, vol. 71, no. 12, pp. e2082-e2089, 2009.

[10] F. E. Browder and W. V. Petryshyn, "Construction of fixed points of nonlinear mappings in Hilbert space," Journal of Mathematical Analysis and Applications, vol. 20, pp. 197-228, 1967.

[11] M. O. Osilike and F. O. Isiogugu, "Weak and strong convergence theorems for nonspreading-type mappings in Hilbert spaces," Nonlinear Analysis: Theory, Methods \& Applications, vol. 74, no. 5, pp. 1814-1822, 2011.

[12] Y. Kurokawa and W. Takahashi, "Weak and strong convergence theorems for nonspreading mappings in Hilbert spaces," Nonlinear Analysis: Theory, Methods \& Applications, vol. 73, no. 6, pp. 1562-1568, 2010.

[13] J. Deepho and P. Kumam, "A modified Halpern's iterative scheme for solving split feasibility problems," Abstract and Applied Analysis, vol. 2012, Article ID 876069, 8 pages, 2012.

[14] J. Deepho and P. Kumam, "Split feasibility and fixed-point problems for asymptotically quasi-nonexpansive mappings," Journal of Inequalities and Applications, vol. 2013, p. 322, 2013.

[15] P. Sunthrayuth, Y. J. Cho, and P. Kumam, "General iterative algorithms approach to variational inequalities and minimumnorm fixed point for minimization and split," OPSEARCH, 2013. 


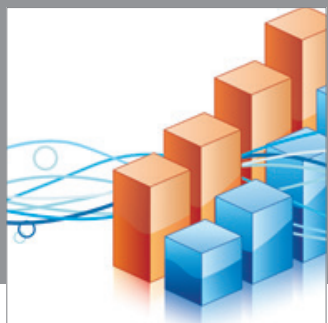

Advances in

Operations Research

mansans

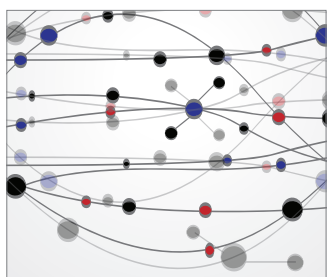

The Scientific World Journal
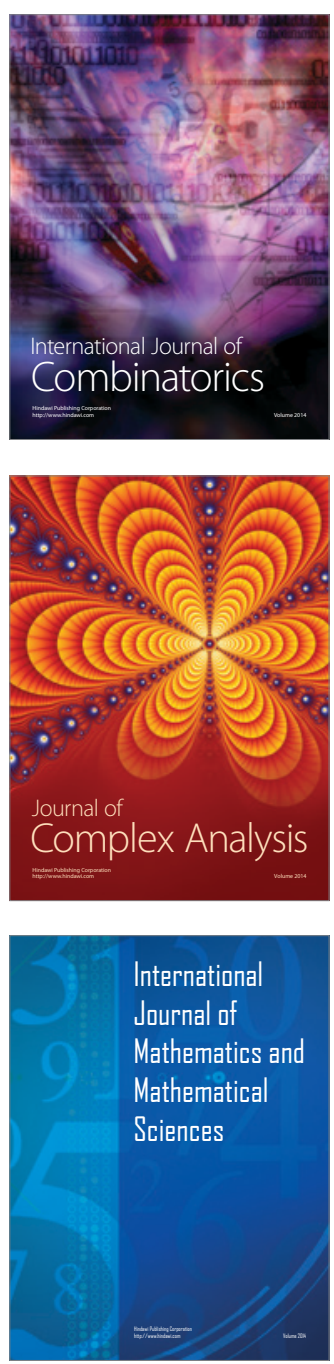
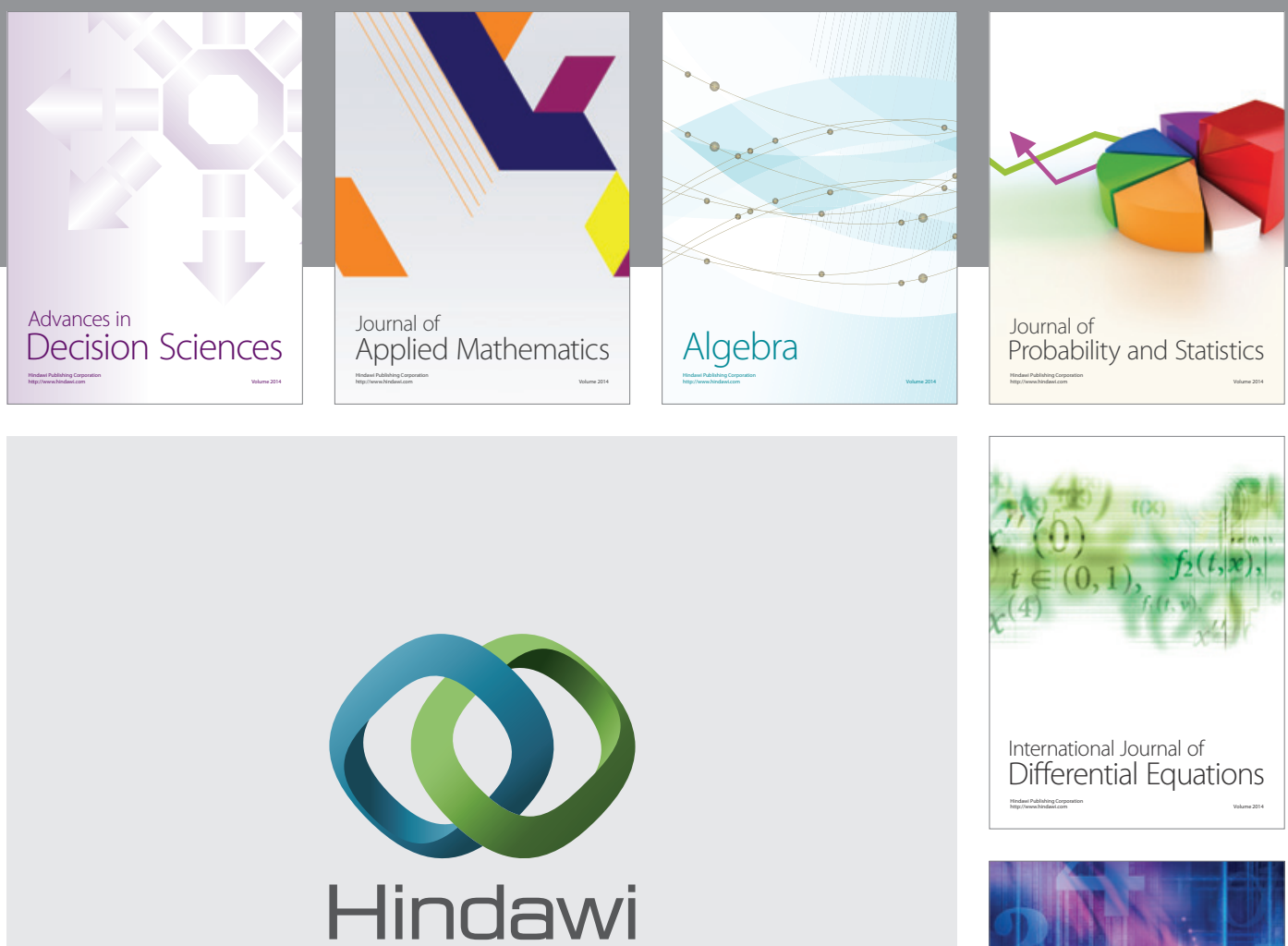

Submit your manuscripts at http://www.hindawi.com
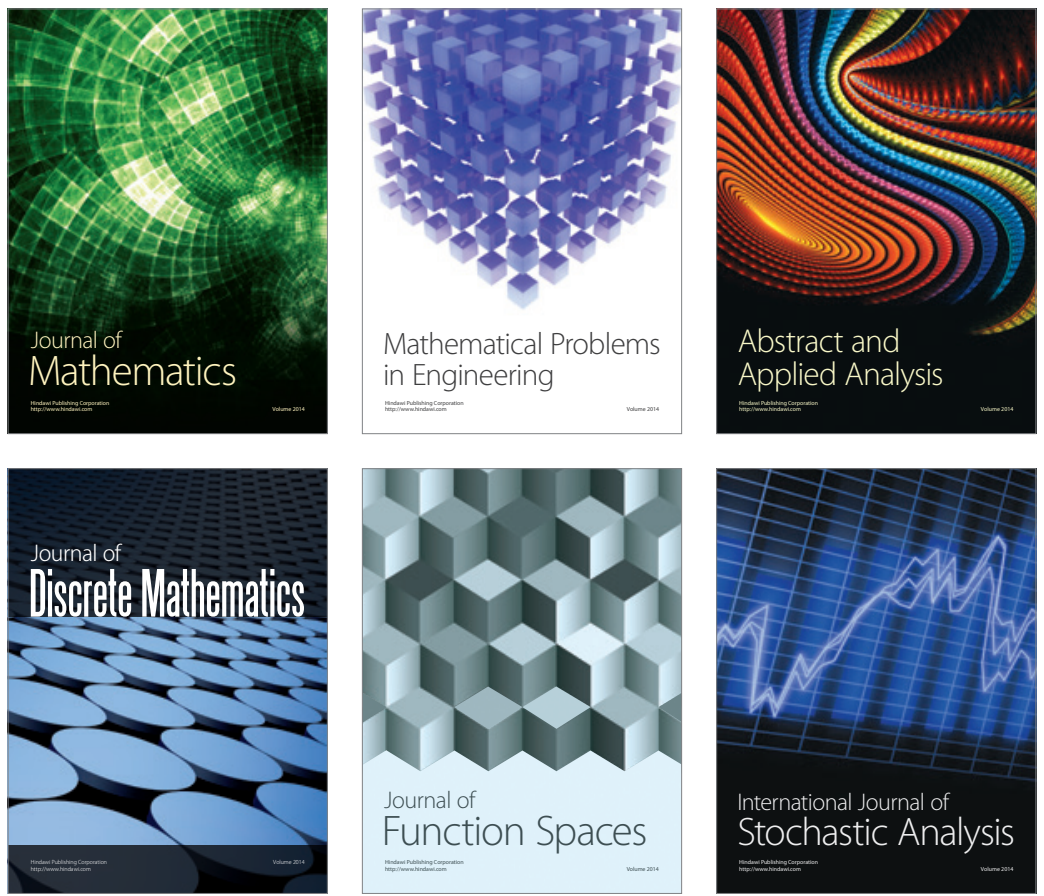

Journal of

Function Spaces

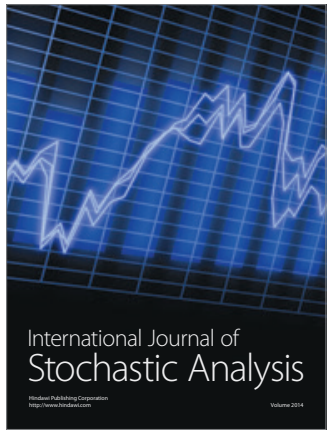

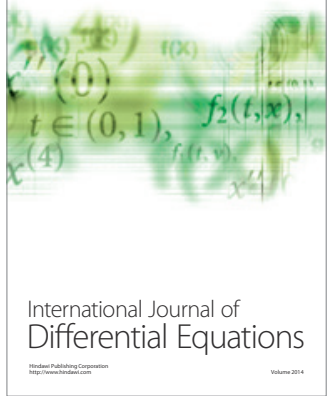
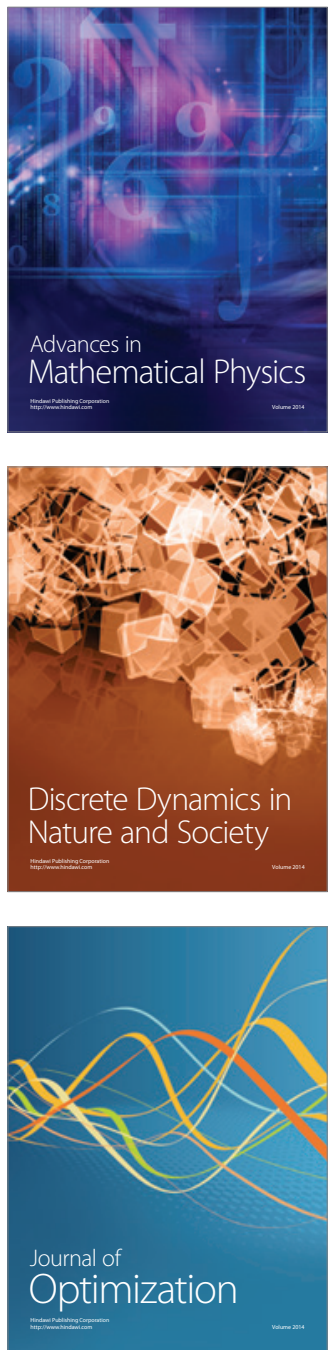